\title{
Meta-Fluorine F 18 \\ Fluorobenzylguanidine
}

National Cancer Institute

\section{Source}

National Cancer Institute. meta-Fluorine F18 Fluorobenzylguanidine. NCI Thesaurus.

Code C120311.

A radioconjug ate composed of the positron-emitting radioisotope fluorine $\mathrm{F} 18$ labeled benzylguanidine, a synthetic analogue of the adrenergic neurotransmitter norepinephrine $(\mathrm{NE})$, with potential use in the diagnostic imaging of human norepinephrine transporter (hNET)-expressing cells by either positron emitting tomography (PET) or computed tomography (CT). Upon administration, meta-fluorine F 18 fluorobenzylguanidine (MFBG) is taken up by and accumulates in both the granules of adrenal medullary chromaffin cells and the pre-synaptic granules of adrenergic neurons in a manner almost identical to that of NE. In turn, hNET -expressing tumor cells can be imaged by PET or CT. hNET, a transmembrane protein and regulator of catecholamine uptake normally restricted to the central and peripheral sympathetic nervous system, is overexpressed in certain tumor cell types. 